\title{
VIVENCIANDO EXPERIÊNCIAS DESENVOLVIDAS COM A GEOGRAFIA NOS ANOS INICIAIS DO ENSINO FUNDAMENTAL
}

\author{
Living experiences developed with geography in the initial years of fundamental education
}

\author{
Denise Wildner Theves* \\ Nestor André Kaercher**
}

*Professora no curso de Pedagogia da UniRitter - denisetheves@gmail.com.

**Docente do PPG em Geografia - UFRGS - nestorandrek@gmail.com.

Recebido em 10/08/2018. Aceito para publicação em 20/08/2018.

Versão online publicada em 03/09/2016 (http://seer.ufrgs.br/paraonde)

\begin{abstract}
Resumo:
Este texto destaca propostas de trabalho desenvolvidas por professoras-estagiárias no sentido de criar possibilidades de ler e compreender o mundo com a Geografia, estabelecendo diálogo com o mundo das crianças. Os trabalhos relatados foram desenvolvidos por professoras-estagiárias durante a realização do Estágio Supervisionado de Docência nos Anos Iniciais do Ensino Fundamental, integrante do III Ciclo de Estudos Interdisciplinares do Curso de Pedagogia do Centro Universitário Ritter dos Reis (Uniritter/POA-RS). Os estágios foram desenvolvidos na perspectiva do enfoque globalizador em que, partindo das vivências e conhecimentos prévios das crianças, foram propostos projetos de ensino com diferentes temáticas. Nestes, os temas da Geografia se apresentam como meios de construção de um trabalho que cria oportunidades de aprendizagens significativas nos Anos Iniciais do Ensino Fundamental.
\end{abstract}

Palavras-chave: Geografia; docência; anos iniciais.

\begin{abstract}
:
This text highlights work proposals developed by trainee teachers in order to create possibilities to read and understand the world with Geography, establishing dialogue with the world of children. The work reported was developed by trainee teachers during the Supervised Teaching Internship in the Early Years of Elementary Education, part of the III Cycle of Interdisciplinary Studies of the Pedagogy Course of the University Center Ritter dos Reis (Uniritter / POA-RS). The internships were developed with the perspective of a globalizing approach in which, based on the experiences and previous knowledge of the children, teaching projects with different themes were proposed. In these, the themes of Geography are presented as means of building a work that creates significant learning opportunities in the Early Years of Elementary School.
\end{abstract}

Key-words: Geography; teaching; initial years.

\section{Introdução}

O presente trabalho visa refletir sobre a importância da produção de conhecimentos com a Geografia nos anos inicias, inserindo-se no âmbito da formação de professores.

Os trechos de trabalho abordados foram desenvolvidos por professoras-estagiárias durante a realização do Estágio Supervisionado de Docência nos Anos Iniciais do Ensino Fundamental, integrante do III Ciclo de Estudos Interdisciplinares do Curso de Pedagogia do Centro Universitário Ritter dos Reis (Uniritter/POA-RS). Os estágios foram desenvolvidos em duplas, durante uma semana, no mês de junho de 2016, em escolas de rede pública (estadual e municipal), em Porto Alegre (RS), em turmas dos Anos Iniciais do Ensino Fundamental. 
Os relatos feitos buscam valorizar, divulgar e refletir com as propostas de trabalho desenvolvidas por professoras-estagiárias no sentido de criar possibilidades de ler e compreender o mundo com a Geografia, estabelecendo diálogo com o mundo das crianças. Com essas reflexões, busca-se destacar a forma pela qual os temas da Geografia se apresentam como meios de construção de um trabalho que cria oportunidades de aprendizagens significativas nos Anos Iniciais.

\section{Desenvolvimento}

0 tema ora estudado insere-se nos trabalhos desenvolvidos com a Geografia durante o Estágio Supervisionado de Docência nos Anos Iniciais do Ensino Fundamental, de alunas do curso de Pedagogia.

Nesse texto, destacam-se trechos de dois trabalhos em que, através da Geografia, inserida nos temas de estudo de um projeto de trabalho ${ }^{1}$, pôde-se ampliar as aprendizagens na leitura e compreensão do mundo. Por outro lado, apresentam-se como uma proposta de articulação entre o ensino superior e a escola, na busca da construção de saberes com a Geografia escolar, no intuito de oportunizar mais qualidade aos saberes docentes.

O envolvimento das estudantes do curso de Pedagogia nesses estágios iniciou através do contato com as escolas e foi desencadeado a partir das seguintes etapas: pesquisa do contexto escolar através do estudo da sala de aula e diagnóstico da realidade; período de observação das crianças na prática educativa desenvolvida pela professora titular na classe de estágio; problematização e delimitação da temática do projeto de trabalho com a turma de alunos; planejamento da prática docente; pesquisa em diferentes fontes de informação, seleção e produção de recursos didáticos para o desenvolvimento da semana de aulas; assessoria junto às professoras do curso de Pedagogia; prática docente na escola; seminário de apresentação das práticas desenvolvidas, elaboração escrita do relatório de estágio.

Os estágios foram desenvolvidos na perspectiva do enfoque globalizador que propõe "organizar os conteúdos a partir de uma concepção de ensino na qual o objeto fundamental de estudo para os alunos seja o conhecimento e a intervenção da realidade" (ZABALA, 2002, p. 35). Nesse contexto, partindo das vivências e conhecimentos prévios das crianças, os projetos desencadeados tiveram os seguintes títulos: Nossas origens - De onde viemos?; Bairro Teresópolis².

\subsection{Projeto: Nossas origens - De onde viemos?}

0 projeto foi desenvolvido em uma turma de $1^{\circ}$ ano, com 24 alunos (11 meninas e 13 meninos), em uma escola da rede pública estadual, em Porto Alegre.

Após as observações realizadas na turma, conversas com a professora foi realizado um momento de problematização junto às crianças. Desse momento as professas- estagiárias relatam:

Notamos que as crianças demonstram muito interesse sobre os diversos países que existem no mundo, principalmente sobre a cultura de cada um. De como vivem, suas vestimentas, seus alimentos, suas línguas, e etc. Notamos que o foco das diferenças, foi para os diferentes jeitos das pessoas viverem, dos diferentes países e não especificamente para as diferenças físicas. E por isso optamos por realizar o projeto com o que percebemos ir ao encontro dos interesses das crianças, pois elas demonstram nitidamente uma curiosidade maior sobre as diferenças culturais. (MOURA, PRATES, 2016, p. 20.)

\footnotetext{
1 A função do projeto é favorecer a criação de estratégias de organização dos conhecimentos escolares em relação ao tratamento da informação e à relação entre os diferentes conteúdos em torno de problemas ou hipóteses que facilitem aos alunos a construção de seus conhecimentos, bem como a transformação da informação procedente dos diferentes saberes disciplinares em conhecimento próprio. (HERNANDEZ; VENTURA, 1998, p. 61).

2 Teresópolis é um bairro de Porto Alegre.
} 
A partir dos interesses demonstrados, foi montada a rede temática que orientou o desenvolvimento do projeto durante uma semana de aulas com esse grupo de alunos do $1^{\circ}$ ano.

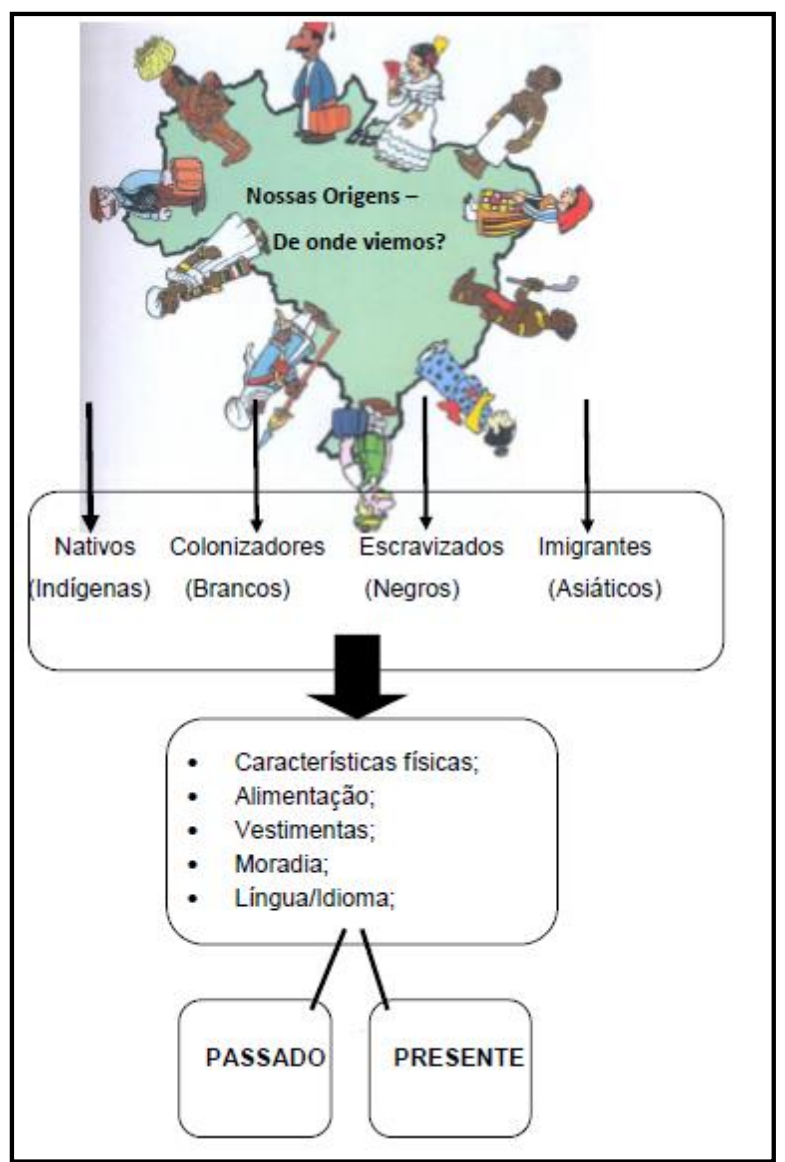

Figura 1: Rede temática

Fonte: MOURA; SOARES (2016, p.17)

Levando em consideração as questões étnicas, a escola, e a Geografia, tem um papel fundamental na construção de novas memórias que estejam livres das amarras do etnocentrismo e do eurocentrismo que durante muito tempo moldaram, e ainda o fazem, nossos modos de ver, sentir e apreender o mundo e o Outro. Se considerarmos que a identidade é construída historicamente, o currículo escolar, também constrói identidades e assim, "produz memória, modos de ser e de conviver". (PEREIRA, 2012, p.7).

Assim, a diversidade pode ser uma riqueza para o trabalho pedagógico se houver possibilidades de criar e implementar propostas pedagógicas que busquem

dar espaço para a diferença e não a busca pela homegeneidade. Ao mesmo tempo, a busca por desmistificar estereótipos e desconstruir preconceitos passa pelo processo de falar sobre as coisas, de tensionar as vivências e o cotidiano para que se possam construir novos saberes sobre as identidades e as diferenças. Eis o que o projeto "Nossas origens - De onde viemos?" propôs.

Através da utilização de músicas, vídeos, imagens, brincadeiras, pesquisas, palestra, leitura de mapas, encenações, contação de histórias, construção de mapa-painel, confecção de objetos e diferentes formas de registro a turma de alunos envolveu-se de forma intensa no projeto e atingiu os objetivos propostos pelas professoras-estagiárias. No relatório do estágio, em suas reflexões sobre o quinto dia de estágio, as professoras-estagiárias relatam o quanto foram significativas as aprendizagens das crianças, bem como a utilização de mapas. 
No momento seguinte, mostramos a rede temática para mostrar que ríamos iniciar outro assunto sobre a rede, que é a dos Imigrantes. Com o auxílio dos bonecos (Indígenas, Africanos, Colonizadores e Imigrantes) e o barco, exploramos o mapa, encenando e conversando sobre a vinda desses diferentes grupos para o Brasil, bem como relembramos o fato de os indígenas já estarem nessas terras. Falamos sobre o porquê de suas vindas para o Brasil, enfatizando as inúmeras dificuldades que viviam naquela época em seus países e por que optaram em virem para o Brasil. Também falamos sobre nossas descendências, de como o Brasil tem inúmeras culturas e diferentes povos. Neste momento pedimos para eles visualizarem o Brasil no mapa, do qual, perguntamos os que moravam no Brasil, quantas pessoas de diferentes culturas haviam vindo e de como deixaram inúmeras heranças para nós. Com isso, aproveitamos e mostramos algumas imagens que representavam as heranças deixadas por cada povo, e depois as colocamos em cima de cada local referente ao mapa. Dessa forma podiam visualizar as imagens no mapa. Encenamos brevemente com o barco localizado em cada lugar e colocamos as imagens dentro do barco, e assim seguimos com ele para o Brasil, enfatizando a todo o momento que cada povo que vinha para o Brasil e trazia um pouco da sua cultura. Era quando deixávamos as imagens que herdamos no Brasil. 0 momento foi bem apreciado pelas crianças que participaram muito. As crianças comentaram sobre a descendência de seus pais e avós. Mostraram que aprenderam e concretizaram muito bem este momento quando iniciamos nosso painel sobre as heranças culturais que foram trazidas pelos Imigrantes e Colonizadores. Neste momento pedíamos para algumas crianças selecionassem para colocar a imagem correspondente a cada povo, e então notamos o quanto foi essencial o mapa e de como ele levou momentos lúdicos para as crianças, assim como os bonecos e o barco que levávamos. Notamos também que foi essencial construir o mapa da forma que fizemos. Afinal, a cada dia registrávamos as aprendizagens do dia num mapa mundi feito em um grande painel. Esse era colocado no chão e ERAM feitos os registros com imagens e palavras-frases elaboradas pelas crianças. (MOURA; SOARES (2016, p. 68-69).

Compreender a ocupação e o povoamento das terras brasileiras e nossas origens, apresenta-se como possibilidade de estabelecer múltiplos olhares sobre esse processo. Os sujeitos envolvidos nesse processo trouxeram diferentes motivações e objetivos, o que muitas vezes provoca tensões e conflitos. Desses (des)encontros foram tramados hábitos e costumes presentes em vários aspectos do dia a dia.

Refletir sobre esse entrelaçado processo nos convoca a repensar elementos que constituem nossa identidade e abrem espaço para a influência dos diferentes grupos étnicos em nosso modo de "ser gaúcho/brasileiro". Callai (1998), ao referir-se à alfabetização, aspecto fundamental no trabalho dos anos iniciais, propõe que esta seja também da experiência humana e indica:

é relevante estudar as relações sociais que se estabelecem entre as pessoas e os distintos grupos sociais; o espaço diferenciado ocupado por um ou outro grupo ou atividade e as relações que se estabelecem; o tempo, como presente vivo e passado vivido, dimensões necessárias para o viver individual e societário. (CALLAI, 1998, p. 61)

\subsection{Projeto: Bairro Teresópolis}

0 projeto foi desenvolvido em uma turma de $3^{\circ}$ ano, em uma escola da rede pública estadual, localizada no Bairro Teresópolis, em Porto Alegre. A turma era composta por 25 alunos (10 meninos e 15 meninas).

0 tema escolhido para o projeto a ser realizado com a turma foi proposto à pedido da professora titular: o Bairro Teresópolis. Ela solicitou que este assunto fosse desenvolvido com os alunos, pois seria continuidade de um projeto que seria desenvolvido por ela. Assim, apesar do tema do projeto ser proposto pela professora, o mesmo foi desenvolvido a partir de uma perspectiva interdisciplinar e com enfoque no interesse da turma, tendo como intuito de fortalecer o sentimento de cuidado e pertencimento ao local em que as crianças moram e estudam. 


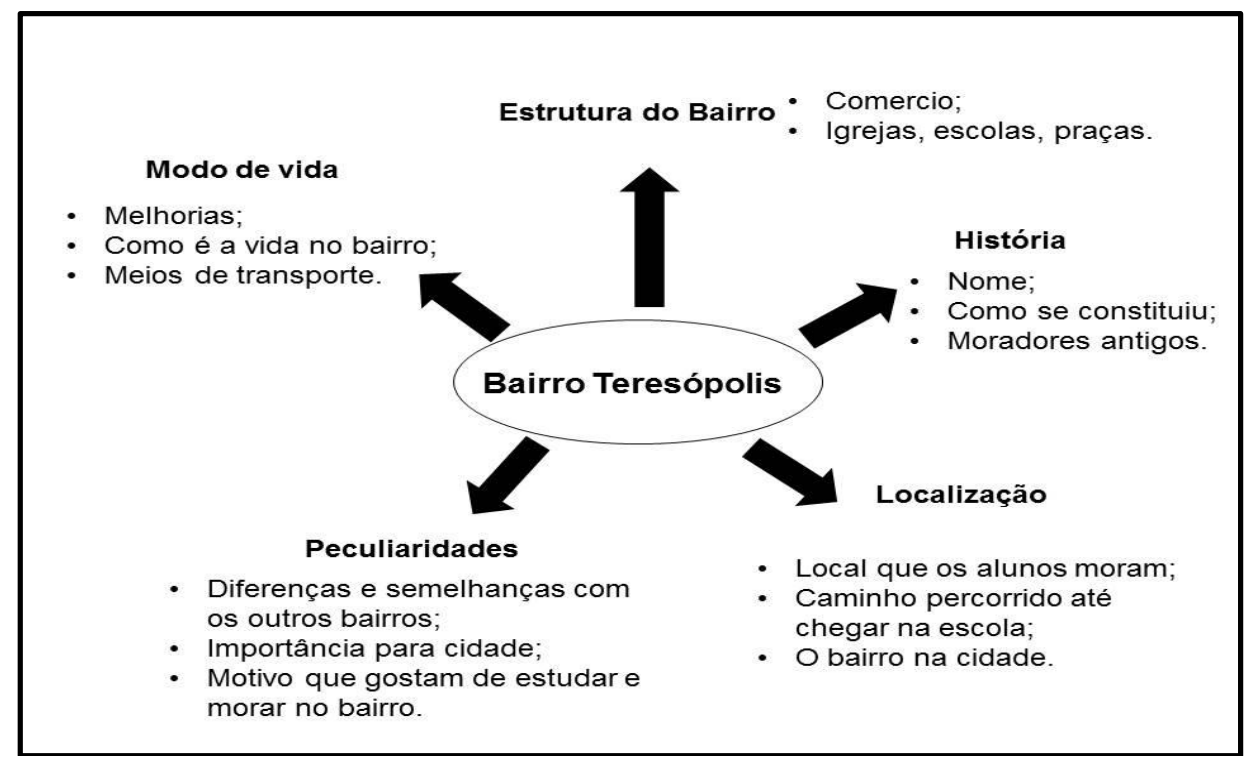

Figura 2: Rede temática

Fonte: MUZZEL; SILVA (2016, p.17)

No segundo dia, as professoras-estagiárias propuseram uma roda de conversa com os alunos a fim de discutir sobre a importância de morar em um local com uma boa infra-estrutura e sobre esses aspectos no Bairro Teresópolis. Após, propuseram a criação de um mapa da Avenida Teresópolis - a principal do bairro. Para essa atividade a turma foi dividida em cinco grupos. Cada grupo recebeu uma cartolina com o mapa da avenida principal do bairro e um material contendo os nomes dos principais estabelecimentos comerciais com suas respectivas logomarcas, algumas árvores, casas e prédios. Então os alunos deveriam encontrar a localização correta desses elementos e colar no cartaz, compondo um mapa do grupo. Também poderiam preencher o cartaz com desenhos de outros elementos da avenida. Posteriormente, cada grupo deveria compartilhar sua criação com os demais colegas.

No relatório do estágio, em suas reflexões sobre esse dia de estágio, as professoras-estagiárias relatam o quanto a problematização sobre o espaço vivido e o trabalho coletivo foram significativos para refletir sobre a espacialidade vivenciada e a representação das mesmas.

Hoje a turma estava um pouco agitada, porém isso não alterou em nada no rendimento dos alunos, todos produziram, participaram e aprenderam bastante. Iniciamos com uma conversa sobre qual era a principal Avenida do Bairro Teresópolis, e depois da resposta dos alunos (a maioria soube responder corretamente) questionamos sobre quais os principais lugares e comércios que localizavam-se naquela região. A turma citou muitos lugares e muitos falaram na "pizzaria", palavra que sempre é citada em todas as questões que trazemos para a aula, pois todos gostam muito de pizzas e têm o hábito de frequentar as pizzarias do bairro.

Após problematizarmos sobre os lugares que existem na Avenida Teresópolis, iniciamos a organização dos grupos para a atividade. Iniciou-se então a distribuição dos materiais e a atividade: a criação do mapa da Avenida Teresópolis. Os alunos estavam um pouco agitados para a realização da tarefa, porém foram fantásticos e empenhados em relação à produção e ao envolvimento para realiza a atividade. Perceberam muito bem o que é realmente um trabalho em grupo dividindo tarefas e ajudando uns aos outros. Assumiram o compromisso de concluir a tarefa, sendo assim, todos os alunos mostraram que tinham conhecimento o suficiente e colocaram isso tudo em prática na criação do mapa.

Tivemos um intervalo para o lanche e na volta os alunos continuaram a trabalhar na atividade. Percebemos que houve uma divisão de tarefas nos grupos. Enquanto alguns coloriam os desenhos, outros recortavam e alguns problematizavam as localizações. Então pedimos a eles que não colassem os desenhos, que apenas posicionassem as imagens onde achavam que era o local correto, pois posteriormente faríamos a problematização juntos. No entanto, um menino 


\begin{abstract}
de um determinado grupo, certo de seu conhecimento prévio orientou seus colegas de grupo, deliberou funções a cada um e completou o mapa corretamente, sem ajuda de nenhuma professora. Demonstrou também ter clareza sobre direita e esquerda, antes e depois e localizou muito bem os espaços. Então iniciamos a problematização com os demais grupos. Colamos no quadro um mapa igual ao deles e contamos uma história de uma pessoa que estava vindo do Centro Histórico para conhecer o bairro e então precisava saber as localizações. Cada lugar/comércio que íamos citando,questionávamos os alunos sobre o local correto no bairro, enfatizando "direita, esquerda, perto e longe" e então os alunos colavam em seus mapas cada desenho juntamente com o andamento da problematização. Após concluirmos o trabalho, foi realizado um seminário sobre esse trabalho e os mesmos foram expostos no corredor da escola. (MUZZEL; SILVA, 2016, p.34-35)
\end{abstract}

Refletir sobre a localização apresenta-se como meio de pensar sobre o espaço e sua representação. Nesse processo, o uso de mapas torna-se essencial e fica evidente o quanto precisa estar presente no trabalho pedagógico desenvolvido nos anos iniciais, afinal "ler o espaço, independente se é real ou mentalmente projetado, é uma capacidade que não se aprende porque se habilita a fazer, se aprende porque se é capacitado para isso" (COSTELLA, 2014, p.193).

Assim, os mapas apresentam-se como recursos para estabelecermos a interação com deslocamentos reais e imaginários entre os lugares. Processo esse que precisa ser vivenciado e não se efetiva pela simples transmissão de informações.

Além do trabalho do segundo dia de estágio relatado, foram propostas outras atividades orais e escritas em que a turma destacou aspectos da Geografia e História do bairro Teresópolis. Essas atividades evidenciaram a importância de, com a Geografia, refletir sobre a "influência do espaço, na fisicidade das coisas e na geograficidade de nossa existência" (Kaercher, 2007, p. 16). Fato evidenciado ao longo do projeto desenvolvido e nas reflexões feitas pelas professoras-estagiárias em seu relatório.

Em História e Geografia, percebemos a importância de não enxergarmos a disciplina de História apenas como um momento de memorização de datas e acontecimentos. 0 estudo da Geografia, não é apenas como um espaço para pintura de mapas, mas sim, a oportunidade dos alunos aprenderem a se localizar no espaço e no tempo. Entender os acontecimentos de nossa História e da Geografia como momentos das próprias vidas, aos quais fazemos parte com poder de mudança, e não apenas meros espectadores. Os alunos compreenderam que todo fato histórico acontecem em algum local, compreendendo a importância do estudo da Geografia nesse processo.Percebemos que os alunos compreenderam muito mais do que o esperado e mostraram-se dispostos a conhecer mais dos fatos históricos e da geografia dos lugares relacionados ao Bairro Teresópolis. (MUZZEL; SILVA, 2016, p. 46-47)

\title{
3. Considerações Finais
}

As propostas de trabalho desenvolvidas com a Geografia nos Anos Iniciais podem constituir-se em possibilidades para o desenvolvimento de uma prática social cotidiana, para a formação de uma consciência espacial, para uma relação ética e estética com o espaço, ampliando suas visões de mundo e a compreensão do que acontece aos alunos e o que vivem. Afinal, com a Geografia e com os alunos podemos ler o mundo de forma plural, contraditória e dinâmica para que possamos compreender melhor a nós mesmos e aos outros. E, quem sabe, contribuir para ações na construção de um mundo digno para todos.

Nesse sentido, a interação que se estabelece entre o professor e os alunos, a definição de como e com quais objetivos as atividades são propostas e como os momentos das aulas acontecem são os elementos que fazem a diferença nos processos de aprendizagem tanto dos docentes como dos discentes.

Assim, o que se enseja é uma busca pela aproximação aos modos de pensar dos alunos dos anos 
iniciais a partir de sua espacialidade, percepções e representações espaciais. Aspectos esses que são fundamentais para a construção de outros olhares sobre o espaço vivido no intuito de propor a leitura do mundo da vida com a Geografia.

Nesse processo, conhecer o cotidiano dos alunos, levar em conta suas vivências e buscar diferentes abordagens para os temas e proposições que compõe o currículo são condições fundamentais para estimular a aprendizagem. Além disso, é fundamental destacar a importância do papel do professor enquanto pessoa que estimula, organiza e propõe atividades a fim de buscar aprendizagens. Trazemos para a escola e levamos dela conhecimentos, valores, emoções, posturas e convicções, sentimentos de nós, dos outros e do mundo. Se a escola forma, a docência também o faz. Assim, a ação pedagógica pode fazer a diferença, do que decorre, a necessidade de uma formação consistente de saberes da Geografia e da Pedagogia.

No nosso entendimento, o objetivo da escola é formar valores como: respeito ao outro, discussão das diferenças, combate às desigualdades e injustiças sociais. Fazer a diferença junto aos alunos e sermos bons professores é a nossa busca. As surpresas que os professores-estagiários provocam em nós, o envolvimento, o que observamos e escutamos deles durante o acompanhamento de sua prática pedagógica nos desafia e alimenta a nossa curiosidade para continuar a busca por um fazer docente de reflexão e ação.

Este texto é o registro de uma caminhada construída na interação de nosso ofício enquanto professores, no conhecimento, nos sonhos. É também um rastro indicando a necessidade de novas leituras da escola e do mundo. É uma marca de que o diálogo entre o ensino superior e a escola, pode ser enriquecedor.

\section{Referências}

CALLAI, Helena C.; CALLAI, Jaeme L. Grupo, espaço e tempo nas séries iniciais. In: CASTROGIOVANNI, Antonio Carlos. et al. (org.). Geografia em sala de aula: Práticas e reflexões. Porto Alegre: Associação dos Geógrafos Brasileiros - Seção Porto Alegre, 1998.

COSTELLA, Roselane. Ensinar o quê...Para quê...Quando... Desafios da geografia na contemporaneidade. In: MARTINS, Rosa E. M.; TONINI, Ivaine M.; GOULART, Lígia B. (org.) Ensino de geografia no contemporâneo: experiências e desafios. Santa Cruz do Sul: EDUNISC, 2014.

HERNANDEZ, Fernando; VENTURA, Montserrat. A organização do currículo por projetos de trabalho. Trad. Jussara Haubert Rodrigues. 5. ed. Porto Alegre: Artes Médicas, 1998.

KAERCHER, Nestor André. Texto: Práticas geográficas para lerpensar o mundo, converentendersar com o outro e entenderscobrir a si mesmo. In: REGO, Nelson. CATROGIOVANNI, Antonio Carlos; KAERCHER, Nestor André. Geografia: Práticas Pedagógicas para o Ensino Médio. Porto Alegre. Artmed, 2007.

MOURA, Michele Fajardo de; SOARES, Rita Prates. Projeto de Trabalho: "Nossas Origens - De onde viemos?". 2016. Trabalho Acadêmico Interdisciplinar VI. Curso de Pedagogia, Centro Universitário Ritter dos Reis (Uniritter), Porto Alegre, 2016.

MUZZEL, Luciana Pinto; SILVA, Priscila Fonseca da. Projeto de Trabalho: Bairro Teresópolis. 2016. Trabalho Acadêmico Interdisciplinar V. Curso de Pedagogia, Centro Universitário Ritter dos Reis (Uniritter), Porto Alegre, 2016.

PEREIRA, Nilton Mullet. Diversidade e diferença: problemas teóricos e pedagógicos. In: KAERCHER, Nestor; TONINI, Ivaine Maria (orgs.). Curso de Aperfeiçoamento Produção de Material Didático para Diversidade. 2. Ed. Porto Alegre: Evangraf, UFRGS. 2012. p. 1-12.

ZABALLA, Antoni. Enfoque Globalizador e pensamento complexo: uma proposta para o currículo escolar. Porto Alegre: Artmed, 2002. 